\title{
The influence of thin benzoate-doped polyaniline coatings on corrosion protection of mild steel in different environments
}

\author{
Ali R. Elkais ${ }^{\mathrm{a}, \mathrm{c}}$, Milica M. Gvozdenovića ${ }^{\mathrm{a}}$, Branimir Z. Jugović ${ }^{\mathrm{b}}$, Branimir N. Grgur ${ }^{\mathrm{a}, *}$ \\ a Faculty of Technology and Metallurgy, University of Belgrade, Karnegijeva 4, 11120 Belgrade, Serbia \\ ${ }^{\mathrm{b}}$ Institute of Technical Sciences of the Serbian Academy of Sciences and Arts, Knez Mihailova 35/IV, 1100 Belgrade, Serbia \\ c University of Elmergib, Chemical Engineering Department, El-Khums, Libya
}

\section{A R T I C L E I N F O}

\section{Article history:}

Received 17 May 2012

Received in revised form 29 August 2012

Accepted 20 December 2012

Available online 18 January 2013

\section{Keywords:}

Polyaniline

Benzoate

Mild steel

Corrosion

Corrosion protection

\begin{abstract}
A B S T R A C T
The corrosion process of mild steel in the presence of benzoate-doped polyaniline coatings exposed to different environments ( $3 \% \mathrm{NaCl}$, atmosphere, and the Sahara sand) has been investigated. This system was also tested for cathodic protection and it has proven more efficient comparing to mild steel alone. Possible mechanisms of the corrosion protection of mild steel in the presence of a polyaniline-based coating in different corrosion media were also proposed.
\end{abstract}

(c) 2013 Elsevier B.V. All rights reserved.

\section{Introduction}

Mild steel is undoubtedly the cheapest and the most commonly used construction material. It has been extensively used for centuries in many areas, for water pipes, boats, docks, tanks, vessels, etc. Because of its low nobility and structural defects, mild steel, in contact with other metals, corrodes practically in all environments [1].

Depending on the corrosion environment, mild steel can be protected in many ways: by applying different organic coatings, by using cathodic or anodic inhibitors, cathodic and anodic protection, etc. These protection procedures imply the following problems: organic coatings are too expensive and can ensure protection for limited periods, depending on the quality of coatings and their thickeness (if scratched, corrosion progresses with catastrophic consequences); inhibitors cannot be applied under certain conditions (e.g. in the protection of water pipes for human use); cathodic protection combined with organic coatings is very expensive due to high electric power consumption; moreover in the case of cathodic protection failure, steel corrodes if organic coatings are damaged.

The application of electroconducting polymers is a relatively new approach in corrosion protection of mild steel in different

\footnotetext{
* Corresponding author. Tel.: +381 11 3303681; fax: +381 113303681 .

E-mail address: BNGrgur@tmf.bg.ac.rs (B.N. Grgur).
}

environments [2-4]. These polymers show a semimetallic conductivity, and yield different effects when applied on metals, especially on mild steel. This is abundantly evidenced in literature, indicating a beneficial corrosion protection of many metals and alloys in different corrosion environments in the presence of conducting polymer-based coatings. Since the mid-1980s, numerous studies have shown that polyaniline-, polypyrrole-, or polythiophenebased coatings lower the corrosion rate of mild steel, stainless steel, aluminum, and copper [2,3]. The conducting polymer can either be applied as a neat coating or as dispersion in a polymer binder [4].

Polyaniline (PANI) is probably the most thoroughly investigated conducting polymer in corrosion protection of mild steel [3] It has been observed, though it is not well investigated, that, unlike regular organic coatings, PANI can protect metal under a scratched or damaged coating surface [5,6]. Many different mechanisms explaining the role of PANI in metal protection have been proposed [3,7-9]. Unfortunately, the mechanism of corrosion protection is still elusive.

Electrochemically deposited benzoate-doped PANI films exhibit good anticorrosion performances for mild steel, aluminum and copper in $3 \% \mathrm{NaCl}$, if applied either individually, or as primer with an epoxy topcoat [10-14].

The aim of this work has been to investigate the corrosion protection of mild steel in the presence of benzoate-doped PANI coatings in different environments, as a model system, in order to propose the possible corrosion protection mechanism and, 


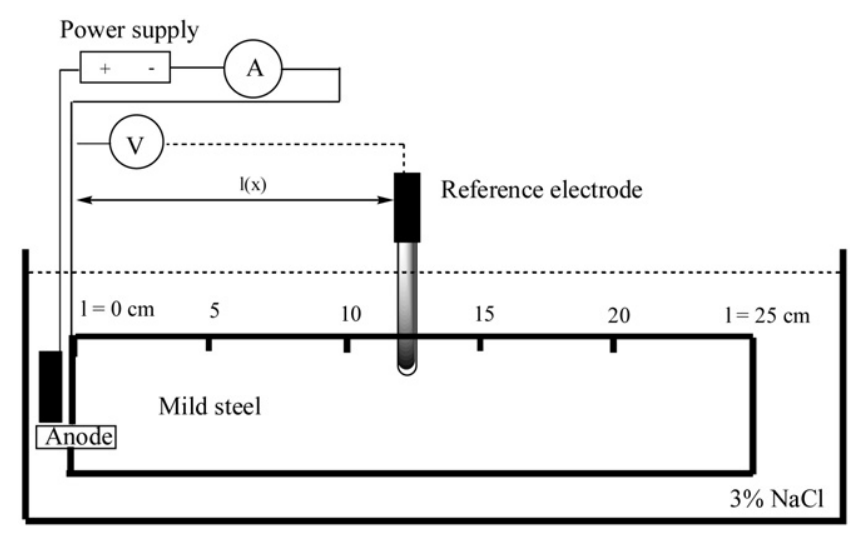

Fig. 1. Schematic presentation of the apparatuses used for cathodic protection experiments.

moreover, to investigate the possibility of a practical application of the proposed coating in cathodic protection.

\section{Experimental}

The electrochemical synthesis of PANI on mild steel (AISI 1212) electrodes was performed at a constant current density of $1.5 \mathrm{~mA} \mathrm{~cm}^{-2}$, from an aqueous solution of $0.5 \mathrm{M}$ Na benzoate (p.a. Merck) and $0.25 \mathrm{M}$ aniline (p.a. Aldrich). Prior to use, aniline was distilled in inert atmosphere. The electrolytes were prepared with doubly distilled water. The mild steel electrodes were mechanically polished with fine emery papers $(2 / 0,3 / 0$ and $4 / 0$, respectively), degreased in acetone and pickled in hydrochloric acid with addition of $0.5 \%$ urotropine (hexa-methylene-tetramine). Electrochemical experiments were carried out at ambient temperature, in three-electrode compartment cell with a saturated calomel electrode used as the reference and Pt wire as a counter electrode. The measurements were performed using PAR 273A potentiostat/galvanostat interfaced to PC.

The potential distribution along the mild steel sample during cathodic protection in $3 \% \mathrm{NaCl}$ was investigated using the apparatuses shown on Fig. 1. The area of the exposed mild steel surface was $75 \mathrm{~cm}^{2}(3 \mathrm{~cm} \times 25 \mathrm{~cm})$. The back side of the electrode was protected with a glued Plexiglas sheet. A titanium-coated ruthenium-oxide electrode with a surface of $1 \mathrm{~cm}^{2}$ was used as anode. The anode was placed near the mild steel sample, at the position denoted as $l=0$.

The corrosion process was investigated in $3 \% \mathrm{NaCl}$, in outdoor atmosphere in downtown Belgrade and the Sahara sand.

Ferroxyl indicator was prepared by dissolving agar-agar in hot distilled water, and adding to it a mixture of phenolphthalein, sodium chloride, and potassium hexacyanoferrate (III). Ferroxyl indicator turns to blue in the presence of $\mathrm{Fe}^{2+}$ ions and pink in the presence of hydroxide ions (from an oxygen reduction reaction), marking anodic and cathodic corrosion zones.

\section{Results}

\subsection{Electrochemical synthesis of benzoate-doped PANI film on mild steel}

In Fig. 2, the anodic polarization curves of mild steel in $0.5 \mathrm{M}$ $\mathrm{Na}$ benzoate solution and with $0.25 \mathrm{M}$ aniline is shown. The corrosion potential of mild steel $\left(E_{\text {corr }}\right)$ in pure $0.5 \mathrm{M}$ Na benzoate solution was $-0.67 \mathrm{~V}$. The active dissolution of mild steel occurred until the potential reached $-0.5 \mathrm{~V}$ with the maximum current density of $0.6 \mathrm{~mA} \mathrm{~cm}^{-2}$. At the potentials more positive than $-0.45 \mathrm{~V}$,

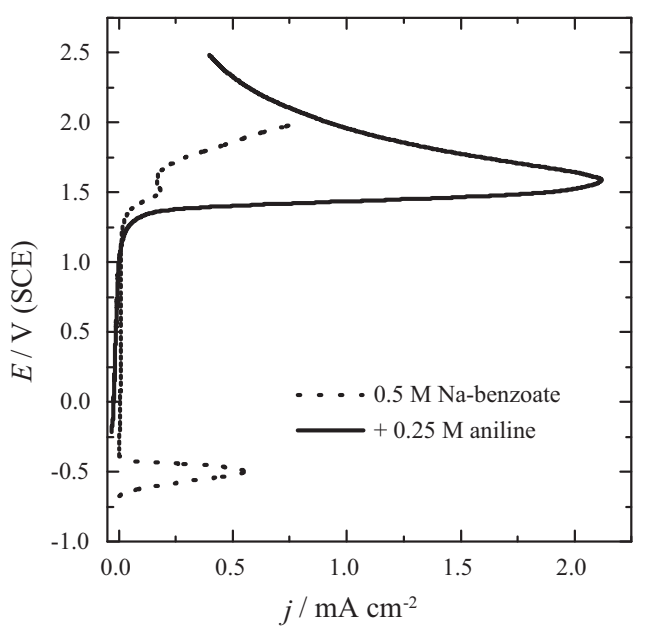

Fig. 2. Anodic polarization curves $\left(v=1 \mathrm{mV} \mathrm{s}^{-1}\right)$ of mild steel in a $0.5 \mathrm{M}$ sodium benzoate solution and with an addition of $0.25 \mathrm{M}$ aniline monomer.

passivation of the electrode occurred with the mean passivation current density of $\sim 5 \mu \mathrm{A} \mathrm{cm}^{-2}$. Transpassive regions accompanied by oxygen evolution were observed at potentials more positive than $1.25 \mathrm{~V}$.

In the presence of aniline, the corrosion potential of the mild steel electrode was shifted positively, to the potential of $-0.25 \mathrm{~V}$. The electropolymerization of aniline on mild steel started at potentials more positive than $1 \mathrm{~V}$, with a pronounced peak at $1.6 \mathrm{~V}$.

The galvanostatic transient of the mild steel electrodes in pure $0.5 \mathrm{M}$ Na benzoate solution with the addition of 0.1 and $0.25 \mathrm{M}$ aniline was given in Fig. 3.

Without aniline in the solution, the potential-time curves had a relatively stable potential plateau, while the induction period was not observed. Applying the current density of $1.5 \mathrm{mAcm}^{-2}$, the potential increased from 1.3 to $2.25 \mathrm{~V}$ during $700 \mathrm{~s}$. After that period, a sharp increase of the potential could be related to the formation of a non-conducting precipitate (e.g. iron benzoate) onto the electrode surface. With aniline in the solution, the polymerization was dependent on the aniline monomer concentration. In a $0.1 \mathrm{M}$ aniline solution, a sharp increase of the potential after $120 \mathrm{~s}$ could be brought into relationship with the diffusion limitation of the aniline monomer. In the solution with $0.25 \mathrm{M}$ of aniline, diffusion limitations were not observed, while a slow increase of the potential, from 1 to $1.25 \mathrm{~V}$, could be related to the polymerization

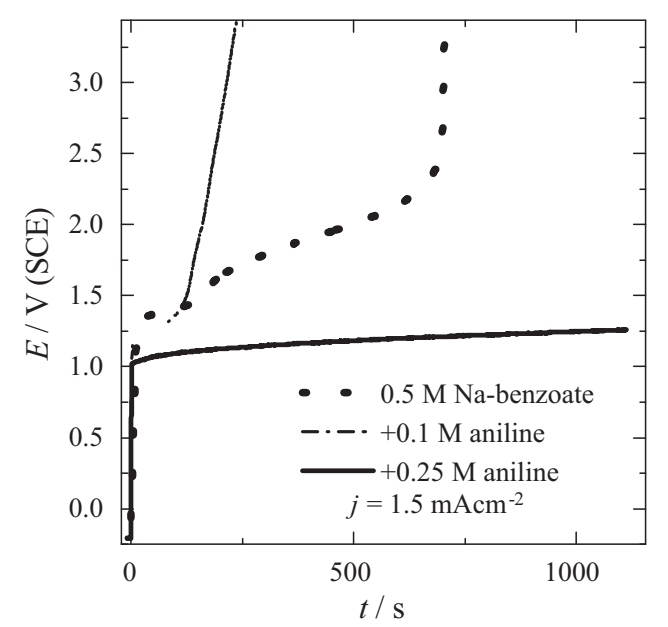

Fig. 3. Galvanostatic transient of the mild steel electrodes in pure $0.5 \mathrm{M}$ Na benzoate solution with 0.1 and $0.25 \mathrm{M}$ aniline. 


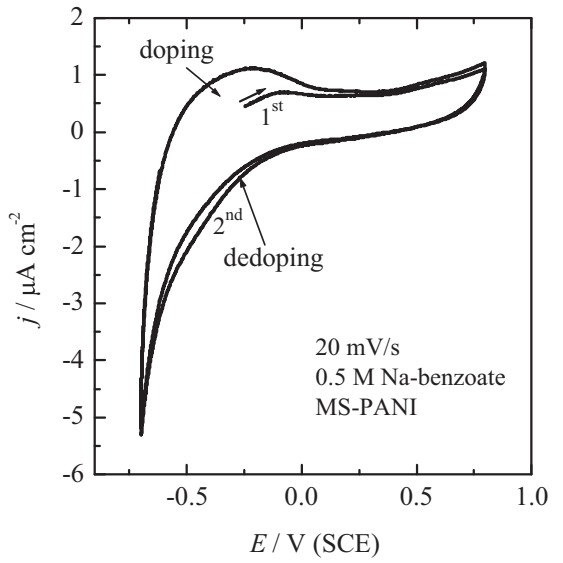

Fig. 4. Cyclic voltammogram of the mild steel - PANI-benzoate electrode in a $0.5 \mathrm{M}$ Na-benzoate solution.

of aniline. The obtained film was black, with good adhesion, determined by cracking. Assuming that the density of benzoate-doped PANI is $1.4 \mathrm{~g} \mathrm{~cm}^{-3}$ [15], and using the equation [16]:

$d=\frac{j t\left(M_{m}+y M_{a}\right)}{(2+y) \rho F}$

where $M_{m}$ and $M_{a}$ are the molar mass of the aniline monomer and benzoate anions, and $y$ the doping degree (the polymerization potential of $1.25 \mathrm{~V}$ suggests that PANI was in the pernigraniline form, $y=1$ ), the thickness of the PANI film has been estimated to be $6 \mu \mathrm{m}$.

Fig. 4 shows cyclic voltammogram of the mild steel (MS)-PANI electrode in a pure $0.5 \mathrm{M} \mathrm{Na}$-benzoate solution. In the anodic scan, in the potential region from -0.6 to $0.1 \mathrm{~V}$, where doping with benzoate anions occurred, the current density was very small: $\sim 1 \mu \mathrm{Acm}^{-2}$. The dedoping of benzoate anions occurred in the broad potential region, from $0.1 \mathrm{~V}$ to $-0.7 \mathrm{~V}$, and was probably overlapped with an oxygen reduction reaction. This means that the MS-PANI system is stable over a large potential range.

\subsection{Corrosion of mild steel and mild steel with electrochemically deposited benzoate-doped PANI film in $3 \% \mathrm{NaCl}$}

The corrosion of mild steel in sea water (simulated with $3 \% \mathrm{NaCl}$ ) is very important for practical applications of this material.

Fig. 5 shows the polarization curves for mild steel and mild steel with benzoate-doped PANI in $3 \% \mathrm{NaCl}$. The anodic polarization curve for the mild steel electrode is characterized by a single slope $\left(0.114 \mathrm{~V} \mathrm{dec}^{-1}\right)$, while the cathodic curve is diffusion-controlled.

The corrosion processes of mild steel is characterized by anodic dissolution of iron

$\mathrm{Fe} \rightarrow \mathrm{Fe}^{2+}+2 \mathrm{e}$

and by the rate determining mixed activation-diffusion-controlled cathodic oxygen reduction:

$\mathrm{O}_{2}+2 \mathrm{H}_{2} \mathrm{O}+4 \mathrm{e} \rightarrow 4 \mathrm{OH}^{-}$

The corrosion current density of $12 \mu \mathrm{A} \mathrm{cm}^{-2}$ for bare mild steel was obtained from the intercept of the anodic Tafel line with the corrosion potential $\left(E_{\text {corr }}=-0.466 \mathrm{~V}\right)$.

After an hour-long immersion in $3 \% \mathrm{NaCl}$, the mild steel electrode with PANI in the doped state had a corrosion potential of $-0.527 \mathrm{~V}$, which is by $70 \mathrm{mV}$ more negative than the corresponding value for a bare mild steel electrode. During the first sweep, the anodic curve had a similar slope as bare mild steel, while the cathodic curve, related to the oxygen reduction reaction and dedoping of benzoate anions, was characterized by a broad peak in

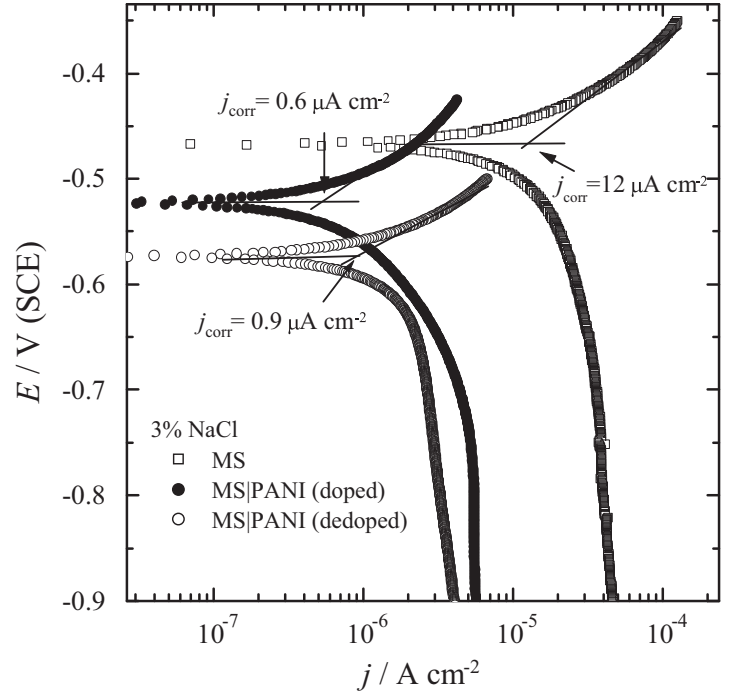

Fig. 5. Potentiodynamic polarization curves $\left(v=1 \mathrm{mV} \mathrm{s}^{-1}\right)$ for mild steel and mild steel with a doped and de-doped PANI film in $3 \% \mathrm{NaCl}$

the potential range from $\sim-0.6 \mathrm{~V}$ to $\sim-0.9 \mathrm{~V}$. After the cathodic polarization (dedoping), the broad peak disappeared, as observed from the polarization curve recorded after the first cathodic sweep. After the cathodic polarization (de-doping), the corrosion potential was shifted to more negative values, $E_{\text {corr }}=-0.573 \mathrm{~V}$, characteristic for the dedoped state of polyaniline. It is interesting to note that the values of the corrosion current density for mild steel with a doped and dedoped PANI film were almost identical: 0.6 and $0.9 \mu \mathrm{Acm}^{-2}$, respectively.

\subsection{Influence of PANI on the cathodic protection of mild steel}

The corrosion of mild steel in sea water is mainly connected to the reduction of dissolved oxygen. The cathodic reaction in nearly neutral solutions is a diffusion-controlled oxygen reduction reaction (Eq. (3)) and the anodic reaction is the dissolution of iron (Eq. (2)),

The theory of cathodic protection is based on the fact that the corrosion potential ( $E_{\text {corr }}$ ) has to be shifted cathodically by applying a current from an external power source that can ensure the minimal polarization to the 'reversible' potential, $E_{r}\left(\mathrm{Fe}^{2+} \mid \mathrm{Fe}\right)$ of iron in the solution, defined by the equation:

$E_{r}\left(\mathrm{Fe}^{2+} \mid \mathrm{Fe}\right)=-0.683+0.029 \log 10^{-6}(\mathrm{vSSCE})$

This minimal polarization, $\Delta E_{\mathrm{min}}^{P}$, is usually $\sim 0.2 \mathrm{~V}$, as it can be seen in Fig. 6. Under such conditions, the dissolution of iron is practically eliminated, and only oxygen reduction occurs on the surface of mild steel. Since corrosion is more efficiently inhibited when polarization is higher, polarization should be as high as $0.45 \mathrm{~V}$. After that, a hydrogen evolution reaction may occur at the potential of $\sim-1.1 \mathrm{~V}$ vs $\mathrm{SCE}, \Delta E_{\max }^{P}$, which can provoke hydrogen penetration into the metal structure and cracking corrosion. Accordingly, the optimum current for mild steel protection should shift the potential of $0.2 \mathrm{~V}$ below the corrosion potential and to approximately $-1.1 \mathrm{~V}$ vs SCE. In Fig. 6 , the experimental polarization curve of mild steel in $3 \% \mathrm{NaCl}$ and the theoretical curves of possible corrosion reactions are shown.

The main idea underlying the following experiments has been to investigate the influence of a benzoate-doped PANI film in cathodic protection and in the event of a failed cathodic protection. The mild steel sample was exposed to a $3 \% \mathrm{NaCl}$ solution. After the stabilization of the corrosion potential, the distributions of the potential 


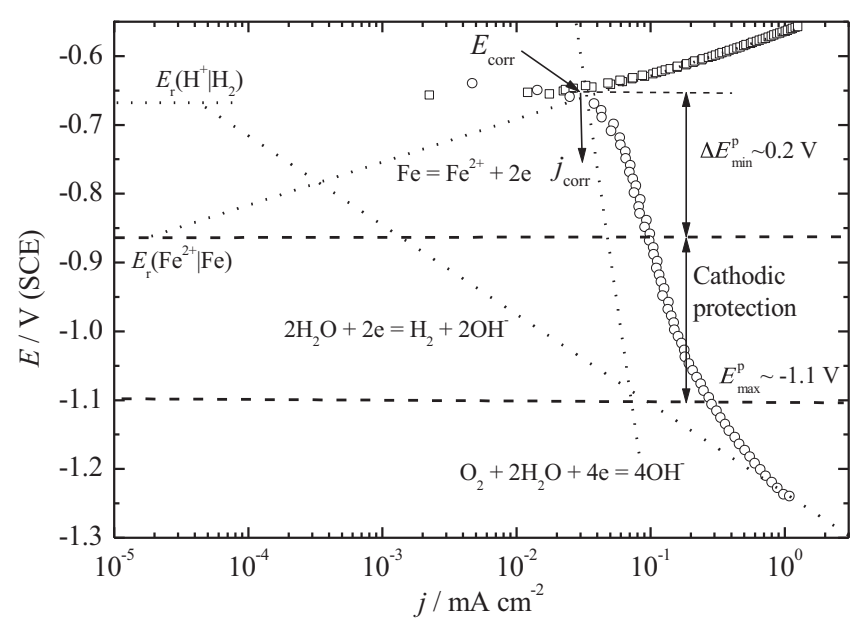

Fig. 6. Polarization curve of the mild steel electrode in a $3 \% \mathrm{NaCl}$ solution, with the theoretical lines of possible corrosion reactions.

along the mild steel sample were measured, for different currents; the results are shown in Fig. 7.

As it can be seen in Fig. 7, for the current densities of 20 and $30 \mathrm{~mA}$, at the position $l=0$ and $5 \mathrm{~cm}$, the potential is below the line where a hydrogen evolution reaction is likely to occur. For the current density of $10 \mathrm{~mA}$, the potential at $25 \mathrm{~cm}$ is near $\Delta E_{\min }^{p}$. Therefore, an optimal current which meets the requirements for an efficient cathodic protection is $\sim 15 \mathrm{~mA}\left(j=0.2 \mathrm{~mA} \mathrm{~cm}^{-2}\right)$.

The experiment shown in Fig. 7 was repeated with a mild steel electrode partially covered with PANI and the results are shown in Fig. 8 .

It can be observed that the MS-PANI system requires a lower cathodic protection current, e.g. $10 \mathrm{~mA}\left(0.13 \mathrm{mAcm}^{-2}\right)$ or even lower than a bare mild steel electrode. This means that the power consumption would be more than $30 \%$ lower than for a bare mild steel electrode.

Fig. 9 features the re-calculated currents, as the current density for $l=0$ and $25 \mathrm{~cm}$ from Figs. 7 and 8, together with the polarization curve of bare mild steel.

It can be seen that for $l=0 \mathrm{~cm}$ practically identical current density-potential dependencies to polarization curve for bare mild steel were obtained. Hence, the optimal current density for

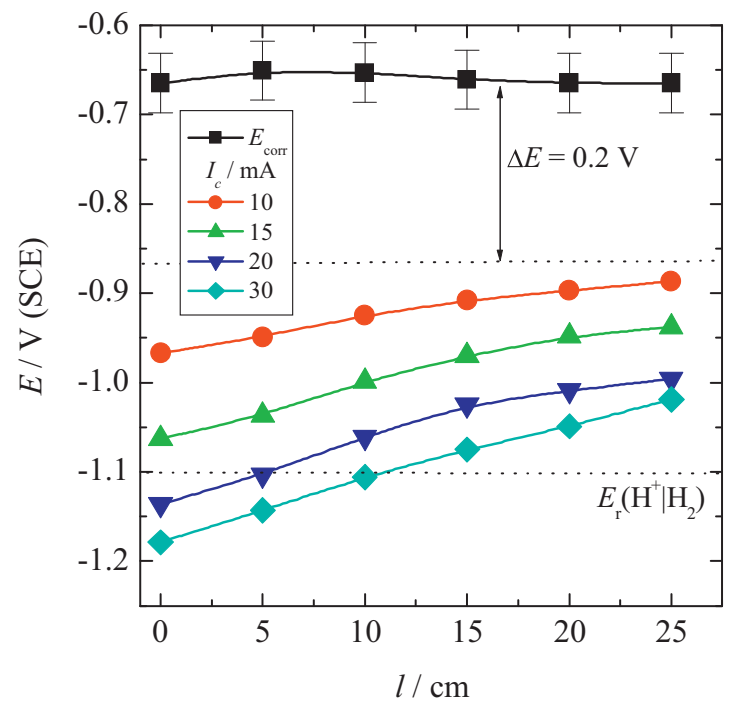

Fig. 7. Dependence of the potential along the mild steel electrode for different currents in a $3 \% \mathrm{NaCl}$ solution.

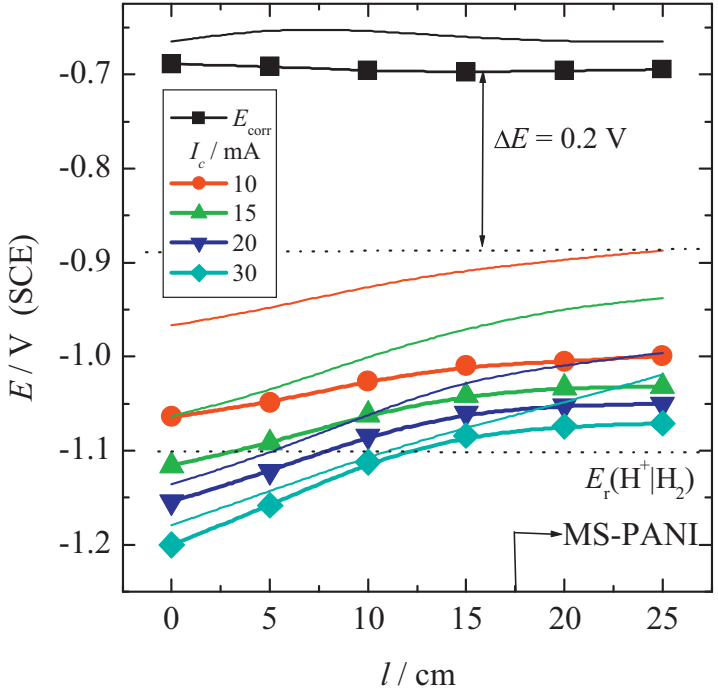

Fig. 8. Dependence of the potential along the mild steel electrode partially covered with PANI for different currents in $3 \% \mathrm{NaCl}$ solution; the lines represent the data from Fig. 7.

the cathodic protection of bare mild steel under the investigated conditions was $0.2 \mathrm{~mA} \mathrm{~cm}^{-2}$. For mild steel partially covered with PANI, the optimal current density for cathodic protection was $\sim 0.1 \mathrm{~mA} \mathrm{~cm}^{-2}$ or $7.5 \mathrm{~mA}$.

Fig. 10 shows the dependence of the potential after the current of $10 \mathrm{~mA}$ was interrupted. It can be seen that the corrosion potential of $\sim-0.7 \mathrm{~V}$ was achieved within a few minutes. Accordingly, the corrosion of mild steel would occur rather rapidly. The experiment was also performed with partially covered mild steel and basically the same results were obtained. As it can be observed, after the current interruption, $\sim 5 \mathrm{~min}$ were required for the potential to reach the value of the corrosion potential.

Fig. 11 shows a comparison of the samples after a 10-hour immersion in $3 \% \mathrm{NaCl}$ at the corrosion potential (simulating cathodic protection failure). It is obvious that mild steel partially covered with benzoate-doped PANI showed extraordinary

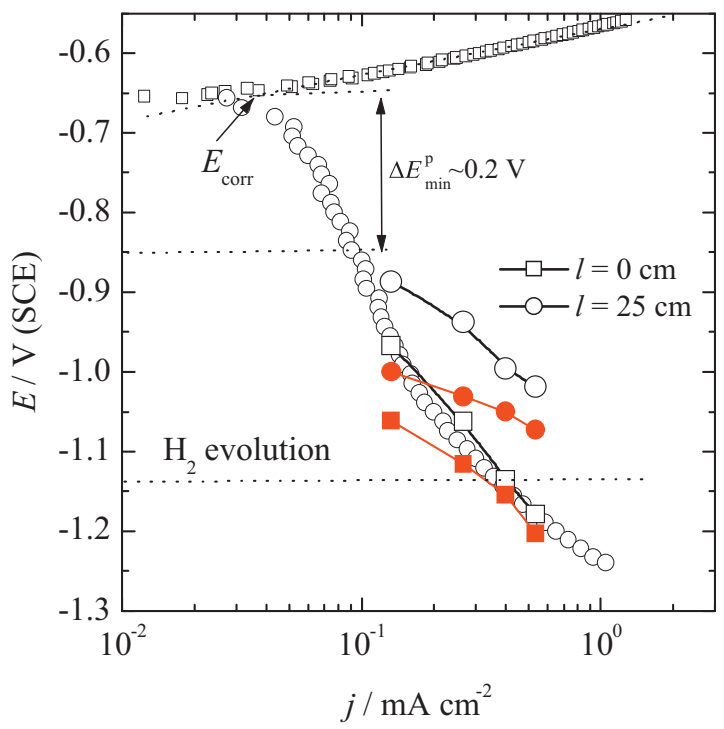

Fig. 9. Polarization curve of the mild steel electrode in a $3 \% \mathrm{NaCl}$ solution with potentials at $l=0$ and $25 \mathrm{~cm}$ for different applied currents (open symbols: mild steel; full symbols: MS/PANI). 


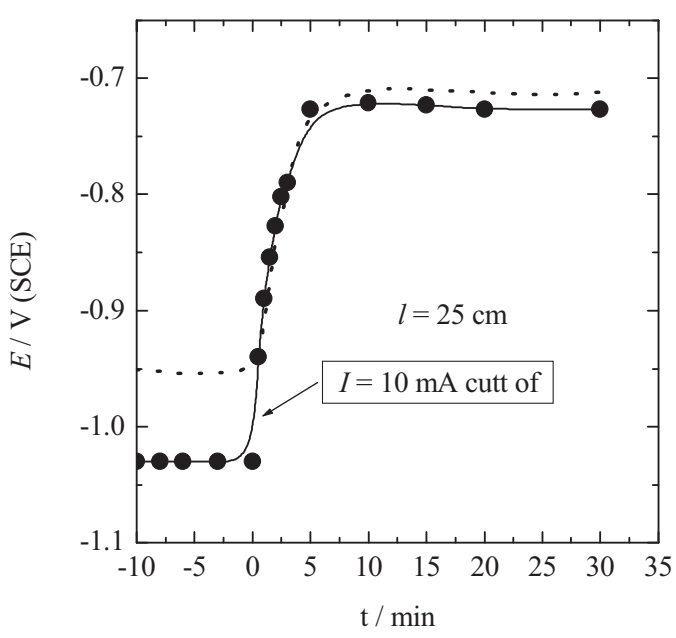

Fig. 10. Dependence of the potential at $l=25 \mathrm{~cm}$ after the current was interrupted for mild steel $(\cdots)$ and mild steel partially covered with polyaniline $(\bullet)$.

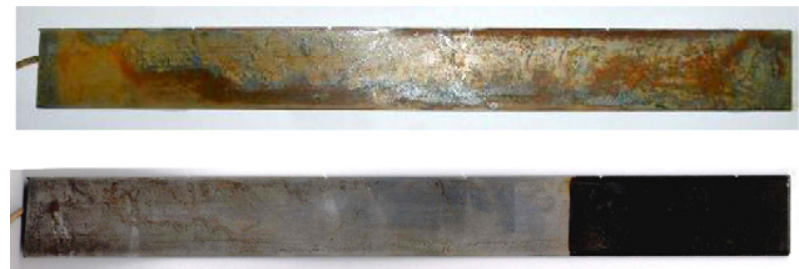

Fig. 11. Comparison of the images of bare mild steel and mild steel with partial PANIbenzoate coatings after a 10 -hour exposure to $3 \% \mathrm{NaCl}$ at the corrosion potential.

protection of mild steel in the case of cathodic protection failure in a $3 \% \mathrm{NaCl}$ solution.

\subsection{Corrosion of mild steel and mild steel-PANI in the Sahara sand}

The corrosion reactions of steel in the Sahara sand are practically the same as in the electrolyte. However, without moisture, corrosion of both samples was slowed down, as it can be seen in Fig. 12.

In the presence of moisture corrosion is facilitated, as it can be seen in Fig. 13, probably due to the composition of the Sahara sand [17]. But even so, corrosion was less pronounced on the sample partially covered with benzoate-doped PANI coating than on bare mild steel.
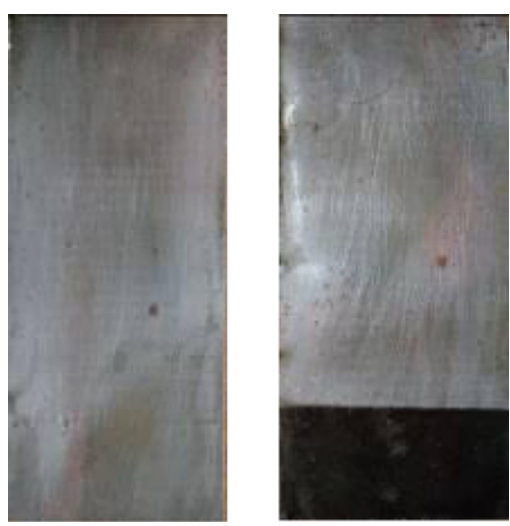

Fig. 12. Images of mild steel (left) and mild steel partially covered with polyaniline (right) after a 60-day exposure to dry Sahara sand.
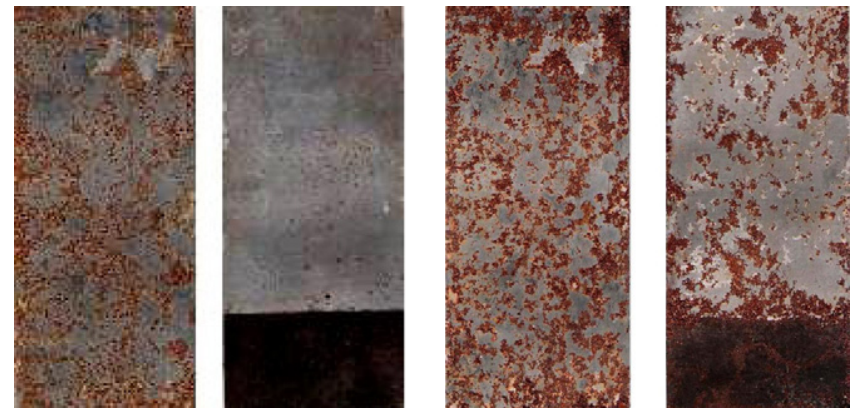

Fig. 13. Images of mild steel and mild steel partially covered with polyaniline after a five-day (left) and ten-day (right) exposure to wet (2.5\%) Sahara sand.

\subsection{Atmospheric corrosion of mild steel and mild PANI-coated mild steel}

Atmospheric corrosion of mild steel and mild steel partially covered with PANI was investigated in Belgrade downtown. As it can be seen in Fig. 14, a partially covered mild steel sample showed much better corrosion resistance compared to unprotected mild steel. It should be noted that during the development of corrosion,
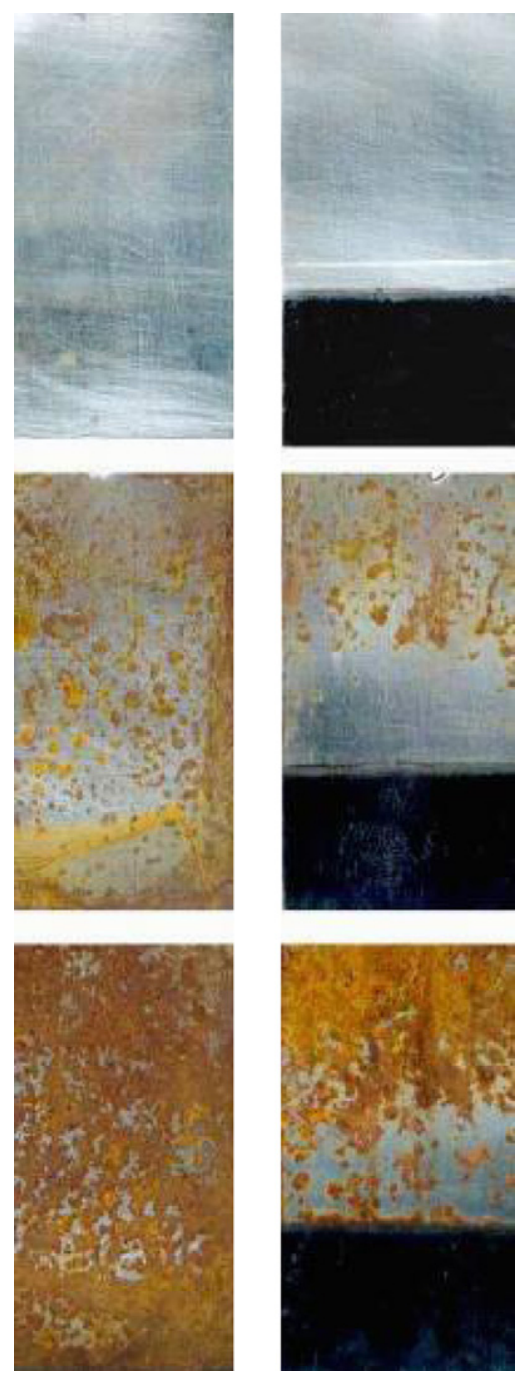

Fig. 14. Images of the mild steel samples after one-day (top), 15-day (middle) and 45-day (bottom) exposure to atmospheric corrosion in Belgrade downtown. Left: bare mild steel, right: mild steel-PANI-benzoates. 


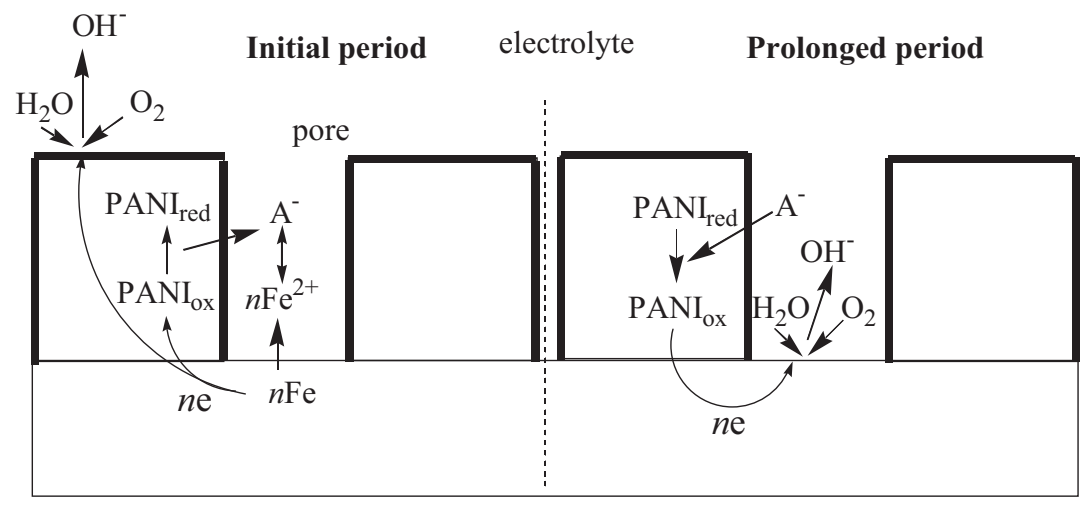

Fig. 15. Proposed mechanism of the mild steel corrosion protection with PANI coatings.

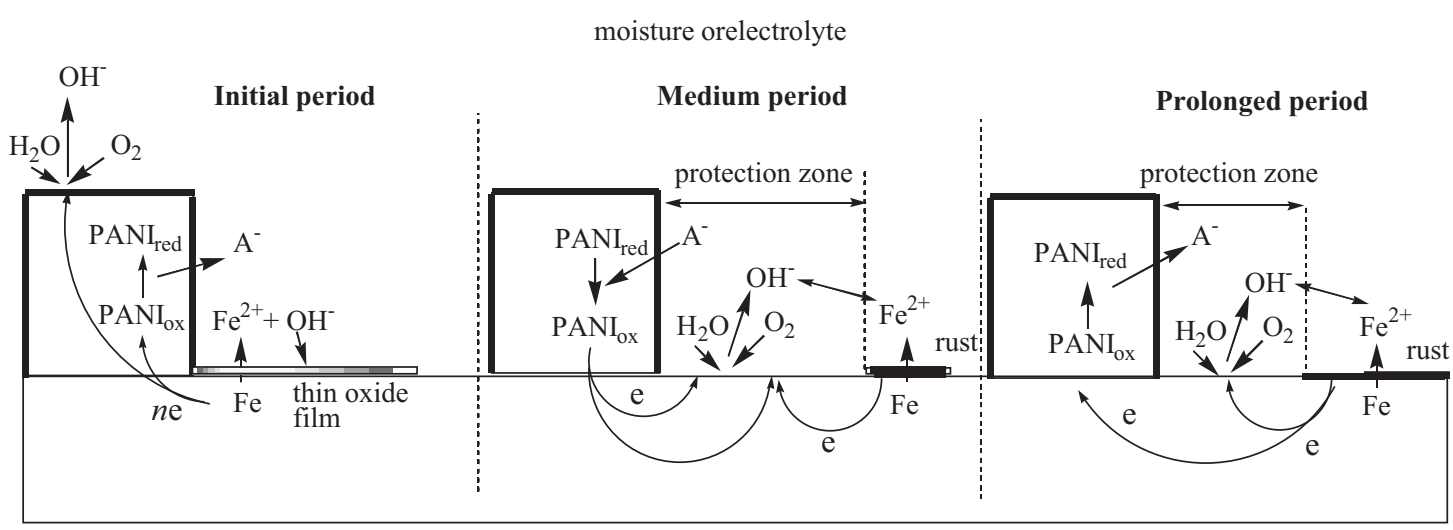

Fig. 17. Proposed mechanism of the mild steel corrosion protection using a partial PANI coating.

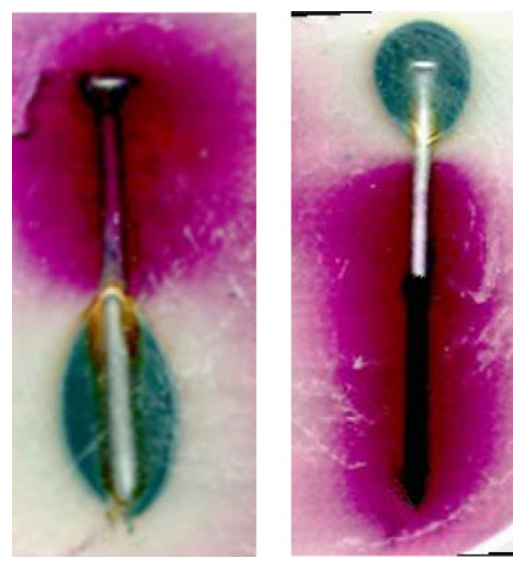

Fig. 16. Ferroxyl indicator test of an unprotected (left) and a PANI-protected nail (right) after $10 \mathrm{~h}$.

the exposed metal surfaces near the polymer coating remained practically without visible corrosion products.

\section{Discussion}

\subsection{Possible mechanism of corrosion protection}

According to the presented results, a mechanism of the mild steel corrosion protection using thin benzoate-doped PANI coatings in different environments could be proposed.

From the polarization experiments (Fig. 5) in $3 \% \mathrm{NaCl}$ it is obvious that PANI is in doped states and that the corrosion potential shifts to negative values, compared to bare mild steel, suggesting a cathodic protection mechanism. It is reasonable to conclude that the corrosion potential of mild steel with a doped PANI film (initial period) is determined by slow cathodic reactions related to the dedoping of benzoate anions and the oxygen reduction reaction on the conducting PANI film:

$$
\begin{aligned}
& {\left[\mathrm{PANI}^{y+}\left(\mathrm{C}_{6} \mathrm{H}_{5} \mathrm{COO}^{-}\right)_{y}\right]_{n}+\text { nye } \rightarrow[\mathrm{PANI}]_{n}+n y \mathrm{C}_{6} \mathrm{H}_{5} \mathrm{COO}^{-}} \\
& \mathrm{O}_{2}+2 \mathrm{H}_{2} \mathrm{O}+4 \mathrm{e} \rightarrow 4 \mathrm{OH}^{-}
\end{aligned}
$$

and the anodic iron dissolution reaction through the pores of PANI. The iron dissolution rate was small due to the slow reaction kinetics of oxygen reduction on the PANI surface. There is also a possibility that the released anions react with $\mathrm{Fe}^{2+}$ in the pores, forming a poorly soluble precipitate.

After most of the anions were released, the corrosion potential of mild steel with a dedoped (low conducting) PANI film could be determined by oxygen reduction as a cathodic reaction at the surface of bare metal in to the bottom of the PANI pores, and the doping of a dedoped PANI film probably with chloride anions:

$$
[\mathrm{PANI}]_{n}+n y \mathrm{Cl}^{-} \rightarrow\left[\mathrm{PANI}^{y+}\left(\mathrm{Cl}^{-}\right)_{y}\right]_{n}+\text { nye }
$$

as an anodic reaction. The electrons released from the PANI films could be transferred through metal, as a cathodic site, where the oxygen reaction takes place. The negative charge of the metal surface induced by electron transfer from the PANI film could prevent anodic iron dissolution near the corrosion potential due to the cathodic protection effect. After a partial doping of the film, the potential shifted to less negative values and the sequences from the initial period could be repeated. Accordingly, this mechanism could 
be designated as the 'switching zone mechanism'. This behavior is schematically presented in Fig. 15.

From the experiments shown in Figs. 11, 13 and 14, it is obvious that the protection effect was not limited only to the metal under the PANI coatings. It is evident that the corrosion of mild steel partially covered with benzoate-doped PANI coating is practically prevented on the bare metal surface near the coating. To investigate this phenomenon, simple ferroxyl indicator test was applied on an unprotected and a PANI-protected nail. From the images shown in Fig. 16, it can bee seen that anodic and cathodic zones on the unprotected nail are well separated. On the contrary, the cathodic zone on the PANI-protected nail is extended along the free metal surface.

From these observations the following mechanism, shown in Fig. 17, could be suggested. Initially, the mechanism is probably similar to the above described one (Fig. 16). The differences is that $\mathrm{Fe}^{2+}$ probably reacts with $\mathrm{OH}^{-}$or dissolved oxygen, producing a thin iron oxide film which has better catalytic properties for the oxygen reduction reaction than PANI and oxide-free iron surfaces. After the de-doping of PANI, a doping reaction may occur in a medium period, driven by an oxygen reduction reaction, but this time occurring on the thin iron oxide layer near PANI. The electrons released in the doping reaction are transferred along free metal surfaces but only to limited distances, due to the current distribution. As a consequence, at some distance after the protected zone, corrosion and rust formation may occur. The electrons formed during iron dissolution could be now involved in the oxygen reduction and the PANI doping reaction (with any kind of the present anions). Over time, the doping/de-doping properties of PANI decrease (due to degradation) and rust continues to grow along the protected metal surface, as it can bee seen in Fig. 14.

\section{Conclusion}

The corrosion of mild steel with partial PANI-benzoate coatings in three different environments $(3 \% \mathrm{NaCl}$, atmosphere and the Sahara sand) has been investigated. It has been concluded that in all of the three investigated environments, benzoate-doped PANI coatings could protect mild steel even when the coatings are partially applied for a limited period of time. It has also been shown that partial benzoate-doped PANI coatings could protect mild steel in the case of a cathodic protection failure. Based on the experimental evidence, the 'switching zone mechanism' has been proposed and discussed in detail.

\section{Acknowledgments}

This study is financially supported by the Ministry of Education, Science and Technological Development of the Republic of Serbia, contract no. H 172046. One of the Authors (Ali Ramadan Elkais) is grateful to the Libyan goverment for his PhD grant.

\section{References}

[1] R.R. Pierre, in: R.W. Revie (Ed.), Corrosion Inspection and Monitoring, Wiley Series in Corrosion, John Wiley \& Sons, Inc., Hoboken, New Jersey, 2007.

[2] D.E. Tallman, G. Spinks, A. Dominis, G.G. Wallace, J. Solid State Electrochem. 6 (2002) 73-84

[3] G.M. Spinks, A.J. Dominis, G.G. Wallace, D.E. Tallman, J. Solid State Electrochem. 6 (2002) 85-100.

[4] G.W. Gordon, M.S. Geoffrey, A.P.K.-M. Leon, R.T. Peter, Conductive Electroactive Polymers Intelligent Polymer Systems, 3rd ed., CRC Press, Taylor \& Francis Group, NY, 2009.

[5] S. Radhakrishnan, N. Sonawane, C.R. Siju, Prog. Org. Coat. 64 (2009) 383-386.

[6] E. Armelin, C. Alemán, J.I. Iribarren, Prog. Org. Coat. 65 (2009) 88-93.

[7] S. Biallozor, A. Kupniewska, Synth. Met. 155 (2005) 443-449.

[8] M. Rohwerder, A. Michalik, Electrochim. Acta 53 (2007) 1300-1313.

[9] T.K. Rout, G. Jha, A.K. Singh, N. Bandyopadhyay, O.N. Mohanty, Surf. Coat. Technol. 167 (2003) 16-24.

[10] M.M. Popović, B.N. Grgur, Synth. Met. 143 (2) (2004) 191-195.

[11] M.M. Popović, B.N. Grgur, V.B. Mišković-Stanković, Prog. Org. Coat. 52 (4)(2005) 359-365.

[12] B.N. Grgur, M.M. Gvozdenović, V.B. Mišković-Stanković, Z. Kačarević-Popović, Prog. Org. Coat 56 (2-3) (2006) 214-219.

[13] M.M. Gvozdenović, B.N. Grgur, Prog. Org. Coat. 65 (3) (2009) 401-404.

[14] M.M. Gvozdenović, B.Z. Jugović, J.S. Stevanović, B.N. Grgur, T.Lj. Trišović, Z.S Jugović, Synth. Met. 161 (13-14)(2011) 1313-1318.

[15] J. Stejskal, I. Sapurina, M. Trchová, E.N. Konyushenko, Macromolecules 41 (2008) 3530-3536.

[16] J. Kankare, in: D. Wise, G.E. Wnek, G.E. Trantolo, T.M. Cooper, J.D. Gresser (Eds.), Electrical and Optical Polymer Systems: Fundamentals, Methods, and Applications, Marcel Dekker, New York, 1998 (Chapter 6).

[17] C. Varlikli, V. Bekiari, M. Kus, N. Boduroglu, I. Oner, P. Lianos, G. Lyberatos, S. Icli, J. Hazard. Mater. 170 (2009) 27-34. 